$$
\text { Oaff } 9506 / 42--2
$$

\title{
Temperature-Dependent Shock Initiation of LX-17 Explosive
}

\author{
R. S. Lee \\ H. H. Chau \\ R. L. Druce \\ K. Moua
}

This paper was prepared for submittal to the 4th International Symposium on Behavior of Dense Media

Under High Dynamic Pressures

Tours, France

June 5-9, 1995

February 1995

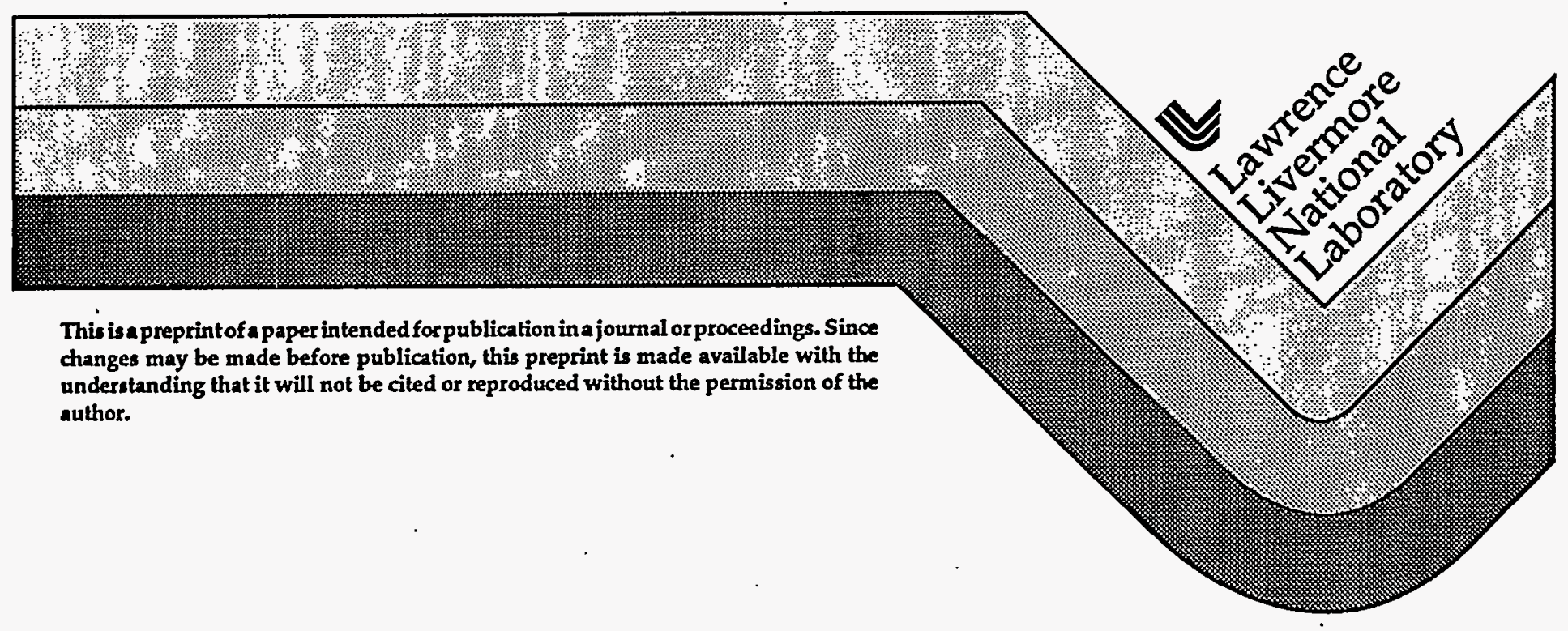




\section{DISCLAIMER}

This report was prepared as an account of work sponsored by an agency of the United States Government. Neither the United States Government nor any agency thereof, nor any of their employees, make any warranty, express or implied, or assumes any legal liability or responsibility for the accuracy, completeness, or usefulness of any information, apparatus, product, or process disclosed, or represents that its use would not infringe privately owned rights. Reference herein to any specific commercial product, process, or service by trade name, trademark, manufacturer, or otherwise does not necessarily constitute or imply its endorsement, recommendation, or favoring by the United States Government or any agency thereof. The views and opinions of authors expressed herein do not necessarily state or reflect those of the United States Government or any agency thereof. 


\section{DISCLAIMER}

Portions of this document may be illegible in electronic image products. Images are produced from the best available original document. 


\title{
Temperature-Dependent Shock Initiation of LX-17 Explosive*
}

\author{
R. S. Lee, H. H. Chau, R. L Druce, and K. Moua \\ Lawrence Livermore National Laboratory \\ Livermore, CA 94550
}

$L X-17$ samples, heated to temperatures up to $250^{\circ} \mathrm{C}$, were impacted by 3 to 10 -mm-wide, 50.8-mm-long strips of 0.13-mm-thick Kapton polyimide film at velocities up to $7.7 \mathrm{~km} / \mathrm{s}$. The Kapton strips were laminated onto a thin alumimum bridge foil and were launched to the desired velocity by discharging a capacitor bank through the foil, causing the foil to explode. The LX-17 samples were confined in a steel holder and heated in an oven to the desired temperature. After the capacitor bank was charged, the LX-17 sample in its steel holder was remotely drawn out of the oven on rails and positioned over the bridgefoil/Kapton-strip laminate. When the sample was in position, the bank was discharged, launching the Kapton strip against the $L X-17$ surface. The shock initiation threshold was measured for 3,7 , and 10 -mm-wide strips at room temperature, $200^{\circ} \mathrm{C}$ and $250^{\circ} \mathrm{C}$. We found a significant reduction in the velocity threshold and in the critical area for initiation when the samples were heated. We compare our results with the earlier data of Bloom (1), who measured the initiation threshold of $L X-17$ over the density range 1.8$1.91 \mathrm{~g} / \mathrm{cm}^{3}$ at room temperature and $-54^{\circ} \mathrm{C} . \mathrm{LX}-17$ has a large coefficient of thermal expansion, as reported by Urtiew, et al. (2), which reduces its density significantly at elevated temperatures. We find that the change of shock initiation threshold with temperature is consistent with the change in sample density, using the relation between threshold and density reported by Bloom.

\section{Introduction}

Explosive formulations based on TATB (1,3,5-trichloro-2,4,6-trinitrobenzene) have proved to be remarkably insensitive to shock and thermal stimuli (3-4). However, hazards do not always confine themselves to a single stimulus. In the work reported here; we have studied the response of LX-17 (92.5\%/7.5\% TATB/Kel-F 800) to the combined stimuli of elevated temperature and shock.

The particular hypothetical scenario which concerned us was that of an airplane crash where a high explosive (HE) charge was engulfed in a fire and a subsequent lightning strike coupled directly into a detonator cable. In this scenario a mechanical safing system keeps the detonator out of line in the initiation train, so the functioning of the detonator is not a concern. With a high-energy source like lightning, there is another concern, because the lightning stroke can deliver sufficient current to explode the detonator cable. If the exploding detonator cable is in close proximity to the charge, a shock can be coupled into the HE and possibly initiate a detonation. The detonator cable of interest was a flat transmission line, so we used the impact of strip flyer plates to simulate the cable explosion effects.

*Work performed under the auspices of the U.S. Department of Energy by the Lawrence Livermore National Laboratory under Contract W-7405-Eng-48 


\section{Experimental Arrangements}

\section{Electric Gun for Launching Strips}

We devised an experimental procedure for launching strips of Kapton polyimide film at a known velocity against a heated $\mathrm{HE}$ target. The well-defined impacts allowed us to relate the HE response to theory and to compare the results with other impact experiments. To launch the Kapton strips we used a device that we call an electric gun. The electric gun has been used extensively for HE shock initiation experiments (5), and has been described in detail in the literature by Chau et al. (6). The electric gun operates by discharging a capacitor bank through a thin aluminum foil that subsequently explodes and drives a sheet of dielectric material to velocities of several $\mathrm{km} / \mathrm{s}$. The Al bridge foil was 5.08 -cm-long, 1.27 -cm-wide, and 0.0508 -mm-thick. The bridge foil and flyer material were laminated into a flat-plate transmission line assembly which was clamped into a short transmission line leading from the capacitor bank.

The Kapton flyer plate material was 0.127 -mm-thick. A 5-cm-long, 10-mm-wide aperture, which we call a barrel, was positioned over the bridge foil and defined the dimensions of the strip flyer. The flyer strips were all 5-cm-long, but had widths of 3,7, or $10 \mathrm{~mm}$. The strip width was varied by interposing a second aperture (segmenter) between the flyer and the target. The segmenter defined the width of the strip that was allowed to strike the target and stopped the unwanted material. The total standoff distance between the surface of the unlaunched flyer and the target was $12.7-\mathrm{mm}$. The experimental arrangement is shown in Fig. 1.

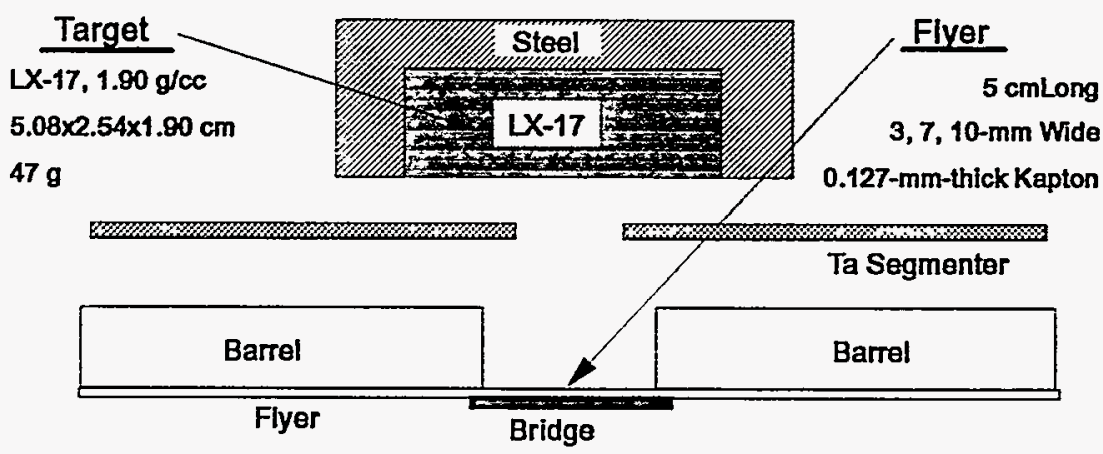

Figure 1. Experimental arrangement for producing strip flyers. The rectangular barrel is 10-mm-across and 5-cm long, producing a 10-mm-wide strip flyer. The Ta aperture (segmenter) allows only the portion of the flyer defined by the open slit to reach the target. In this view, the current is flowing toward or away from the observer.

\section{Method for Heating HE Samples}

We wished to determine the shock initiation threshold for strip impacts from room temperature up to $250^{\circ} \mathrm{C}$. Above $250^{\circ} \mathrm{C}$ the TATB begins to decompose, so we did not conduct experiments above this temperature. It was necessary to construct an oven and 
a transport method to position the hot HE over the electric gun laminate, as is shown schematically in Fig. 2.

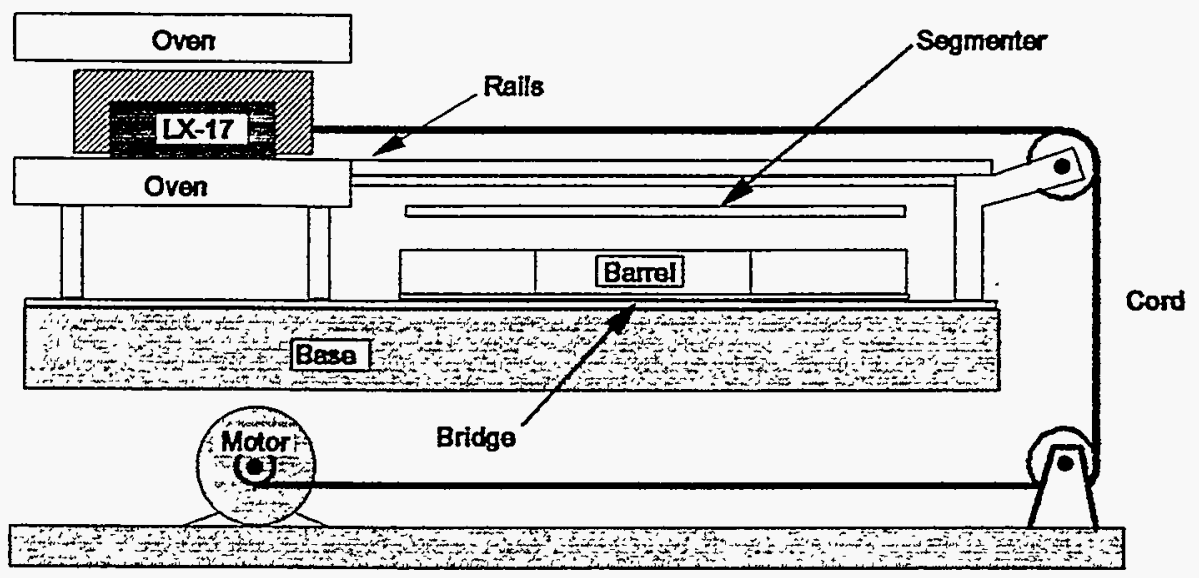

Figure 2. Schematic diagram of the apparatus used to heat and position the target over the electric gun laminate. In this drawing, rotated $90^{\circ}$ from the drawing in Fig. 1, the current flows through the bridge from left to right.

The LX-17 samples, 5.08-cm-long with a 2.54-cm-square cross section were mounted into a steel sample holder. The sample holder walls were 7.94-mm-thick and fastened into a box structure with steel machine screws. Thermocouples were mounted in several locations to monitor temperature.

The heating oven was constructed from two cylindrical heating bands mounted together to form a tubular oven with an inner diameter of about $5.1 \mathrm{~cm}$. A programmable controller allowed the oven temperature to be ramped up to a desired temperature and maintained to allow the sample to reach equilibrium. Power to the oven was transferred through a high-voltage relay, which was opened before the shot was fired to prevent the possibility of a high-voltage discharge back through the power cord to the oven.

\section{Firing the Shot}

When the sample had equilibrated at the desired temperature, the power to the heaters was interrupted by opening the high voltage relay and the bank was charged to the desired firing voltage. The thermal capacity of the furnace and the steel holder maintained the temperature while the bank was being charged. The sample block, sliding on steel rails, was pulled out of the oven by a string and pulley arrangement and the bank was discharged through the electric gun laminate. About 5 seconds were required to position the sample block over the barrel, and the sample did not cool by more than about $1^{\circ} \mathrm{C}$. Detonation of the HE shatters the steel plates of the sample holder. If the sample does not detonate, the HE is pulverized, but the steel plates are not fractured.

\section{Strip Velocity Calibration Curves}

The first experimental task was to determine the calibration curve for strip velocity vs bank charging voltage. This was done for the $10-\mathrm{mm}$-wide strips using a Fabry-Perot laser velocimeter to measure the strip velocity as a function of time. The calibration curve 
is shown in Fig. 3. The velocity-time curves can be integrated to give velocity vs distance from which the velocity with which the flyer strikes the HE can be determined. When a segmenter is used to produce 7-mm and 3-mm-wide strips, the same calibration curve can be used because the segmenter simply clips off the edges of a 10-mm-wide strip. At the maximum strip velocity of $7.7 \mathrm{~km} / \mathrm{s}$, the calculated impact pressure and pulse duration for a LX-17 target at room temperature are $55 \mathrm{Gpa}$ and $20 \mathrm{~ns}$, respectively.

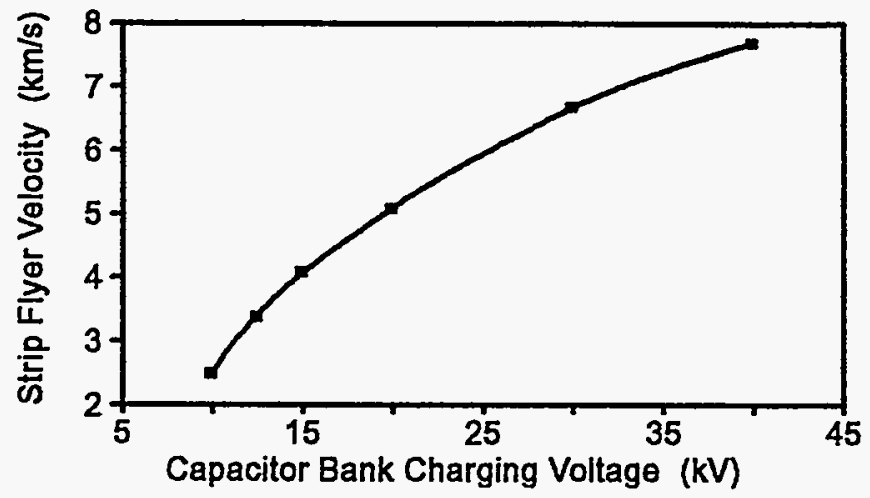

Figure 3. Velocity calibration curve for the strip flyers as a function of bank charging voltage.

\section{Shock Initiation Threshold Measurements}

The objective of the experiments was to determine the shock initiation threshold of $\mathrm{LX}-17$ as a function of strip width and temperature. One begins by choosing a firing voltage at which the sample is expected to detonate. If a detonation occurs when the shot is fired, one then chooses a lower voltage. Otherwise, the voltage is raised for the next shot. Succeeding voltages are chosen depending on whether a detonation did or did not occur on the previous shot. For efficiency and for statistical purposes, a protocol must be established for choosing firing voltages. We used a procedure developed by Neyer (7).

At room temperature $\left(20^{\circ} \mathrm{C}\right)$ the threshold velocity for the $10-\mathrm{mm}$-strips was 5.4 $\mathrm{km} / \mathrm{s}$, in good agreement with the data for 2.54-cm-diameter, 0.13-mm-thick Kapton flyers reported by Honodel et al. (4). We found that we could not initiate the LX-17 with 7mm-wide strips at the maximum strip velocity of $7.7 \mathrm{~km} / \mathrm{s}$. This finding is consistent with the work of Jackson, et al. (3), who reported that the threshold for 0.25 -mm-thick, round, Kapton flyers rose sharply when the flyer diameter was reduced below $10 \mathrm{~mm}$.

At $250^{\circ} \mathrm{C}$, the threshold dropped to $3.3 \mathrm{~km} / \mathrm{s}$ for both the $10-\mathrm{mm}$-wide and $7-\mathrm{mm}$ wide strips. At this temperature the LX-17 is still less shock sensitive than high-density HMX-based explosives at room temperature (PBX-9404 has a velocity threshold of about $2.6 \mathrm{~km} / \mathrm{s}$ for $0.13-\mathrm{mm}$-thick, 2.54-cm-diameter, round Kapton flyers (8)). The threshold of the $3-\mathrm{mm}$-wide strips was higher, at $4.9 \mathrm{~km} / \mathrm{s}$. It is clear that at $250^{\circ} \mathrm{C}$ the critical area for initiation has decreased significantly. The decrease in critical initiation area means that $\mathrm{LX}-17$ at $250^{\circ} \mathrm{C}$ is considerably more vulnerable to shock initiation by electrical explosions of flat cables and by small, high-velocity fragments than at room temperature. 
We performed a very limited number of experiments to determine the shape of the threshold velocity vs temperature curve for the three strip widths. At $200^{\circ} \mathrm{C}$ the threshold curve for the $10-\mathrm{mm}$ and $7-\mathrm{mm}$-wide strips rose to $3.7 \mathrm{~km} / \mathrm{s}$ and the threshold for the 3mm-wide strips was still the same as at $250^{\circ} \mathrm{C}$ to within experimental error. The threshold data are given in Table I and shown graphically in Fig. 4.

\begin{tabular}{c|ccc}
\hline Thickness: & $3 \mathrm{~mm}$ & $7 \mathrm{~mm}$ & $10 \mathrm{~mm}$ \\
\hline Temperature & & & \\
& $\begin{array}{c}\text { Velocity } \\
(\mathrm{km} / \mathrm{s})\end{array}$ & $\begin{array}{c}\text { Velocity } \\
(\mathrm{km} / \mathrm{s})\end{array}$ & $\begin{array}{c}\text { Velocity } \\
(\mathrm{km} / \mathrm{s})\end{array}$ \\
$20^{\circ} \mathrm{C}$ & & $>7.7$ & $5.4 \pm 0.2$ \\
$200^{\circ} \mathrm{C}$ & $4.9 \pm 0.4$ & $3.7 \pm 0.2$ & $3.7 \pm 0.2$ \\
$250^{\circ} \mathrm{C}$ & $4.9 \pm 0.4$ & $3.3 \pm 0.2$ & $3.3 \pm 0.2$ \\
\hline
\end{tabular}

Table I Velocity initiation thresholds for the impact of 5-cm-long, 0.13-mm-thick Kapton strips on $\mathrm{LX}-17$.

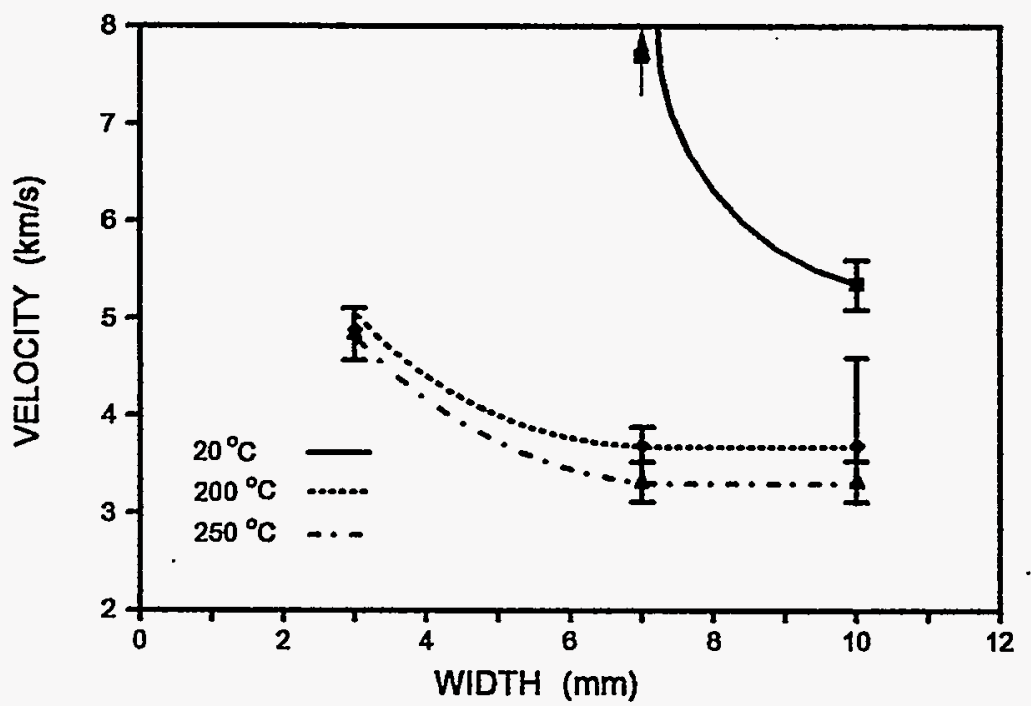

Figure 4. Threshold data summary. The error bars represent the highest "no-go" and the lowest "go." For the 7-mm strip fired at room temperature, the result was a "no-go" so the arrow indicates that the threshold curve lies above this point. For the 3-mm sample at $200^{\circ} \mathrm{C}$, the lowest "go" was the same as at $250^{\circ} \mathrm{C}$. More shots would be required to distinguish between the 200 and $250^{\circ} \mathrm{C}$ points.

\section{Discussion}

The lowering of the shock initiation threshold of TATB formulations has been previously reported by Dallman and Wackerle (9) and Urtiew et al. (2). Dallman and Wackerle measured the run to detonation in hot PBX-9502 (95\%/5\% TATB/Kel-F-800) 
as a function of input shock pressure using explosive plane-wave drivers as shock wave generators. Urtiew et al. used a gas gun to produce the shock wave stimulus and measured the evolution of the detonation wave using embedded gauges. Both sets of investigators reported a significant lowering of the shock initiation threshold. The results reported here are consistent with the findings reported in $(2,9)$. A significant new result is the reduction in critical initiation area that we observed at elevated temperatures. Because of the strip geometry of the flyer, we cannot quantify the critical initiation area. The critical strip width was reduced by a factor of more than two and one might expect that the critical initiation diameter for circular flyers would be reduced by the same amount. The reduction in critical initiation area along with the decrease in shock initiation threshold means that hot TATB formulations are considerably more vulnerable to initiation by small, high-velocity fragments than they would be at room temperature. We must point out again that these TATB formulations, heated to near their decomposition temperature, are still less vulnerable than $\mathrm{HMX}$ formulations at room temperature.

The mechanisms responsible for the reduction of threshold are still not completely understood. Urtiew et al. have suggested that increased porosity and a reduction in the critical size of "hot spots" play a role. In a recent paper (2) they measured the anisotropic thermal expansion of LX-17 and found a volume thermal expansion of about $9 \%$ at $250^{\circ} \mathrm{C}$. It is indeed plausible that such a large increase in porosity would have a significant effect on the shock initiation threshold.

The effect of density on the shock initiation threshold of LX-17 has been studied by Bloom (1), who measured the shock initiation threshold of LX-17 made from several different batches of TATB powder. He used the impact of circular Kapton flyer plates, 2.54-cm in diameter and $0.25-\mathrm{mm}$-thick, as the shock initiation stimulus. Bloom made his measurements both at room temperature and at $-54^{\circ} \mathrm{C}$. If thermally induced changes in porosity are responsible for the temperature dependence of the shock initiation threshold, one should be able to correct our data and the low temperature of Bloom so that the data fall on the same curve of shock initiation threshold vs density. We used a different thickness impactor than Bloom, so it was necessary to use some sort of initiation criterion to compare our data. Figure 5 shows a plot of the log of impact pressure, $\mathrm{P}$, at threshold vs pulse duration, $\tau$, for impactors of different thickness. The data are from Honodel et al. (4). In computing pressures and pulse lengths, the thickness of adhesive layers and ablation of the flyers during flight was not taken into account. The high-pressure points, i.e., points corresponding to $0.051-, 0.13-$ and 0.25 -mm thick flyers, lie approximately on a straight line when the data are plotted on a log-log plot. A linear regression fit corresponds to the condition that $\mathrm{P}^{2.14} \tau=$ constant, as shown by the solid line in Fig. 5 . Also shown is the line $\mathrm{P}^{2} \tau=$ constant, indicated by the dashed line. There is not much difference between the fits, so we used the $\mathrm{P}^{2} \tau=$ constant criterion to compare our data with the data of Bloom. To calculate pressure and pulse duration, we used the $U_{s}-u_{p}$ Hugoniot reported by Green (3) for the full-density LX-17 (1.90 g/cm and above). We used Herrmann's model for compaction of porous materials (10) to calculate Hugoniots for the lower density materials.

In Fig. 6 we plot our data and the data of Bloom (1) as $\mathrm{P}^{2} \tau$ versus the percentage of theoretical maximum density (\%TMD) to which the samples were pressed. In Fig. 6 the \%TMD is not corrected for thermal expansion. Fig. 7 shows $\mathrm{P}^{2} \tau$ at initiation threshold 


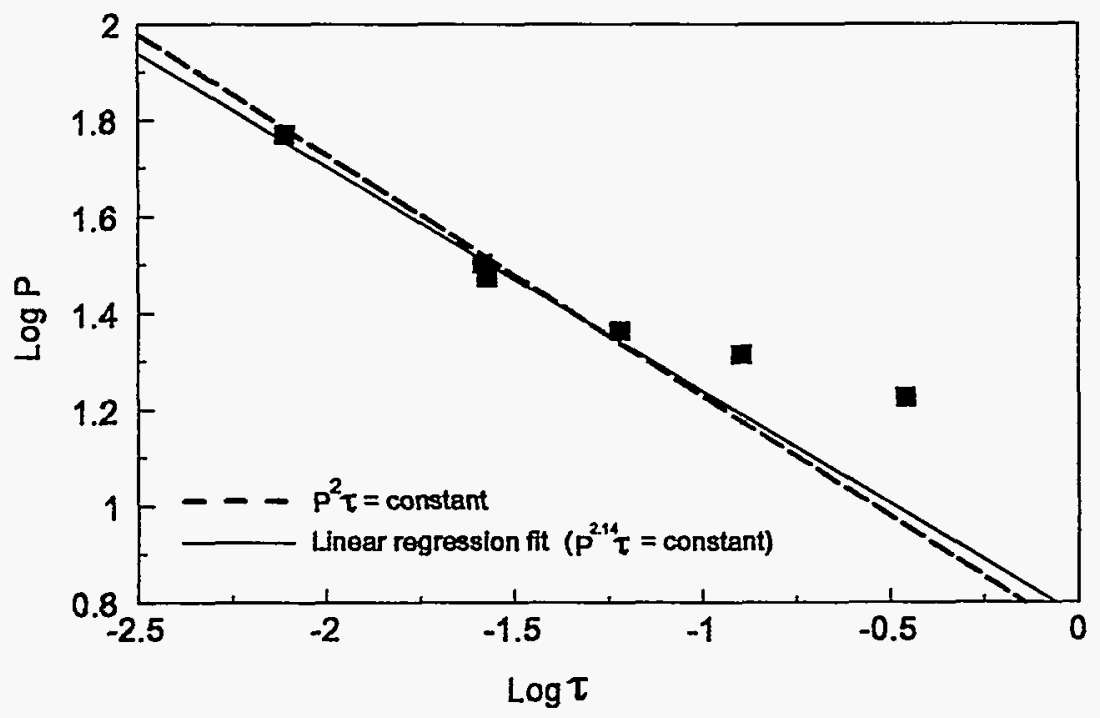

Figure 5. Log of impact pressure at threshold vs pulse duration for a number of different thickness impactors. The data are from Honodel et al. (4). The solid line corresponds to the condition $\mathrm{P}^{2.14} \tau=$ constant, and the dashed line to the condition $\mathrm{P}^{2} \tau=$ constant.

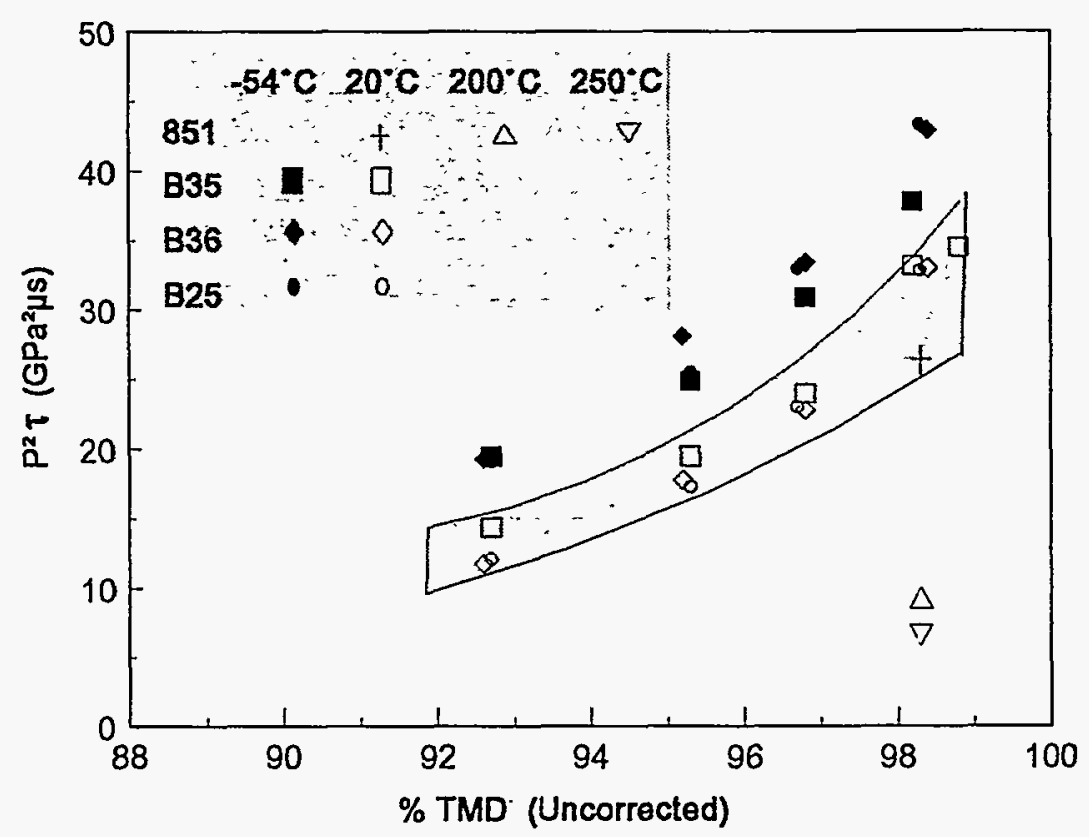

Figure 6. $\mathrm{P}^{2} \tau$ at initiation threshold as a function of \%TMD. Lot 851 was the lot of LX17 used for the present studies. B36, B35 and B25 were lots of production-grade LX-17 studied by Bloom (1). The shaded area represents the range of data in (1) at $20^{\circ} \mathrm{C}$. 
as a function of $\% \mathrm{TMD}$, corrected for thermal expansion of the sample. Correcting the TMD for thermal expansion collapses all of the data into a single band only slightly wider than the range of the $20^{\circ} \mathrm{C}$ data in (1). Even the data at $250^{\circ} \mathrm{C}$ falls into line. It is clear that the change in the shock initiation threshold of LX-17 with temperature is consistent with what one would expect from the change in porosity of the samples due to thermal expansion. All of the data used in Fig. 5 and Fig. 6 are listed in Table II.

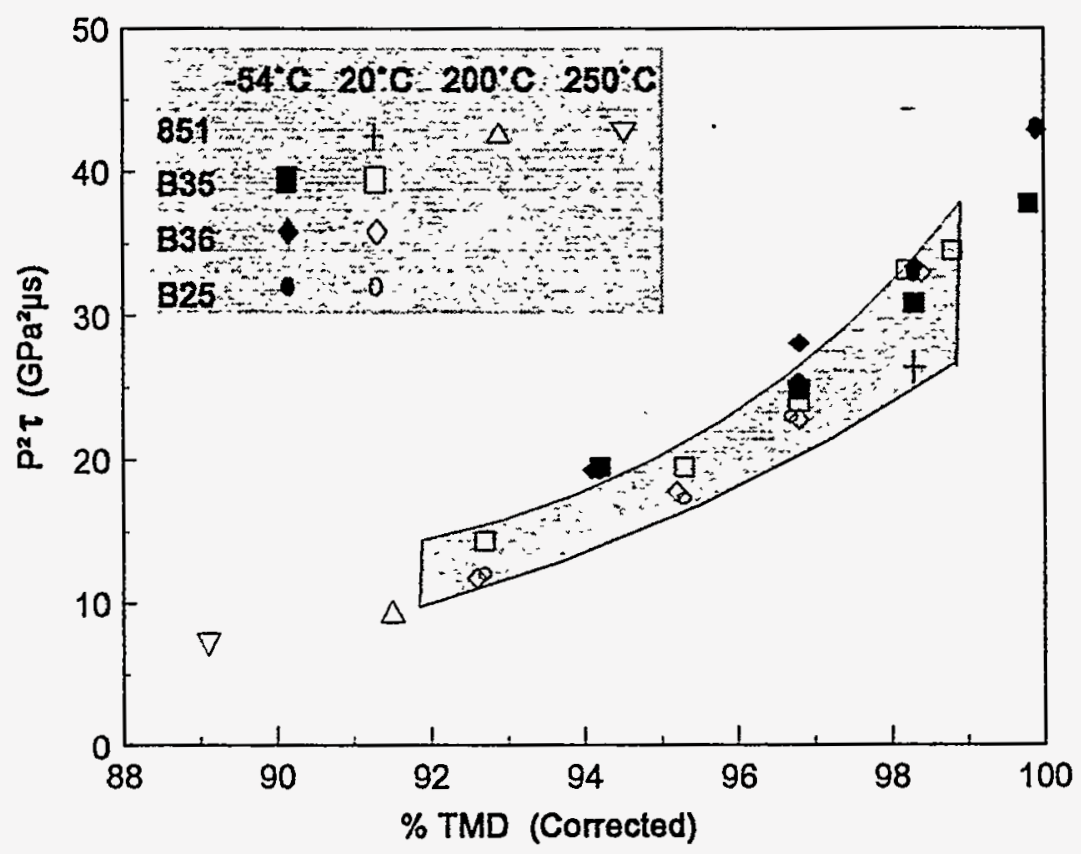

Figure 7. $\mathrm{P}^{2} \tau$ at initiation threshold as a function of $\% \mathrm{TMD}$, corrected for thermal expansion of the sample. Correcting the TMD for thermal expansion collapses all of the data into a single band only slightly wider than the range of the $20^{\circ} \mathrm{C}$ data in (1).

\section{Summary and Conclusions}

LX-17 samples, heated to temperatures up to $250^{\circ} \mathrm{C}$, were impacted by 3 to $10-$ mm-wide, 50.8 -mm-long strips of 0.13 -mm-thick Kapton polyimide film at velocities up to $7.7 \mathrm{~km} / \mathrm{s}$. The LX-17 samples were confined in a steel holder and heated in an oven to the desired temperature. The shock initiation threshold was measured for 3, 7, and 10-mmwide strips at room temperature, $200^{\circ} \mathrm{C}$ and $250^{\circ} \mathrm{C}$. We found a significant reduction in the velocity threshold and in the critical area for initiation when the samples were heated. We compare our results with the earlier data of Bloom (1), who measured the initiation threshold of LX-17 over the density range $1.8-1.91 \mathrm{~g} / \mathrm{cm}^{3}$ at room temperature and $-54^{\circ} \mathrm{C}$. LX-17 has a large coefficient of thermal expansion, as reported by Urtiew, et al. (2), which reduces its density significantly at elevated temperatures. We find that the reduction of shock initiation threshold with temperature is consistent with the change in sample density, using the relation between threshold and density reported by Bloom. 


\section{Acknowledgments}

We gratefully acknowledge the permission of George Bloom to use his raw data from Ref. (1) in our paper.

\section{References}

1. K Bahl, G. Bloom, L. Erickson, R. Lee, C. Tarver, W. Von Holle and W. Weingart, "Shock Initiation of TATB Formulations", Proc. 7th Symposium (Int.) on Detonation, NSWC MP 82-334, Naval Surface Weapons Center, White Oak, MD (1981).

2. P. Urtiew, T. Cook, J. Maienschein and C. Tarver, "Shock Sensitivity of IHE at Elevated Temperatures", Proc. 10th Symposium (Int) on Detonation, (1993) - to be published.

3. R. Jackson, L. Green, R. Barlett, W. Hofer, P. Kramer, E. Nidick, Jr., L. Shaw and R. Lee, "Initiation and Detonation Characteristics of TATB", Proc. 6th Symposium (Int.) on Detonation, ACR-221, Office of Naval Research, Arlington, VA, (1976).

4. C. Honodel, R. Humphrey, R. Weingart and R. Lee, "Shock Initiation of TATB Formulations", Proc. 7th Symposium (Int.) on Detonation, NSWC MP 82-334, Naval Surface Weapons Center, White Oak, MD, (1981).

5. R. Weingart, R. Lee, R. Jackson and N. Parker, "Acceleration of Thin Flyers by Exploding Metal Foils", Proc. 6th Symposium (Int.) on Detonation, ACR-221, Office of Naval Research, Arlington, VA, (1976).

6. H. Chau, G. Ditbenner, W. Hofer, C. Honodel, D. Steinberg, J. Stroud, R. Weingart and R. Lee, "The Electric Gun, a Versatile Tool for High-Pressure Shock Wave Research", Rev. Sci. Instrum., 51, 1676 (1980).

7. B. T. Neyer, "More Efficient Sensitivity Testing", Rept. MLM-3609, EG\&G, Mound Applied Technologies, Miamisburg, OH (1989).

8. R. Weingart, R. Jackson, and R. Lee, "Shock Initiation of PBX-9404 by ElectricallyDriven Flyer Plates", Propellants and Explosives, 5, 158, (1980).

9. J. Dallman and J. Wackerle, "Temperature Dependent Shock Initiation of TATB-Based High Explosives", Proc. 10th Symposium (Int) on Detonation, (1993) - to be published.

10. W. Herrmann, "Dynamic Compaction of Porous Materials", J. Appl. Phys. 40, 2490 (1969). 


\begin{tabular}{|c|c|c|c|c|c|c|c|}
\hline Material & Density & Density & \%TMD & \%TMD & $\mathrm{V}(\mathrm{th})$ & $\mathrm{P}(\mathrm{impact})$ & $\mathrm{P}^{2} \tau$ \\
\hline & $\left(\mathrm{g} / \mathrm{cm}^{3}\right)$ & $\left(\mathrm{g} / \mathrm{cm}^{3}\right)$ & & & $(\mathrm{km} / \mathrm{s})$ & $(\mathrm{GPa})$ & $\left(\mathrm{GPa}^{2} u \mathrm{~s}\right)$ \\
\hline & $20^{\circ} \mathrm{C}$ & Corrected & $20^{\circ} \mathrm{C}$ & Corrected & & & \\
\hline B35@20을 & 1.9210 & & 98.8 & & 4.54 & 24.5 & 34.6 \\
\hline B35 & 1.9096 & & 98.2 & & 4.47 & 23.8 & 33.2 \\
\hline B35 & 1.8809 & & 96.8 & . & 3.93 & 19.1 & 23.5 \\
\hline B35 & 1.8519 & & 95.3 & & 3.68 & 16.9 & 19.5 \\
\hline B35 & 1.8014 & & 92.7 & & 3.32 & 14.0 & 14.4 \\
\hline B36@20ㄷ & 1.9122 & & 98.4 & & 4.46 & 23.8 & 33.0 \\
\hline B36 & 1.8814 & & 96.8 & & 3.85 & 18.5 & 22.4 \\
\hline B36 & 1.8515 & & 95.2 & & 3.55 & 16.0 & 17.8 \\
\hline B36 & 1.7998 & & 92.6 & & 3.06 & 12.3 & 11.8 \\
\hline B25@20ㄷ & 1.9119 & & 98.3 & & 4.45 & 23.7 & 32.8 \\
\hline B25 & 1.8808 & & 96.7 & & 3.86 & 18.6 & 22.5 \\
\hline B25 & 1.8526 & & 95.3 & & 3.51 & 15.7 & 17.3 \\
\hline B25 & 1.8016 & & 92.7 & & 3.1 & 12.6 & 12.1 \\
\hline $851 @ 200^{\circ} \mathrm{C}$ & 1.90 & 1.778 & 98.3 & 91.5 & 3.7 & 16.3 & 9.6 \\
\hline $851 @ 250^{\circ} \mathrm{C}$ & 1.90 & 1.732 & 98.3 & 89.1 & 3.33 & 13.3 & 6.9 \\
\hline $851 @ 20^{\circ} \mathrm{C}$ & 1.90 & & 98.3 & & 5.35 & 31.9 & 27.1 \\
\hline 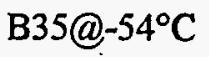 & 1.9096 & 1.9405 & 99.8 & 99.8 & 4.69 & 25.9 & 37.8 \\
\hline B35 & 1.8809 & 1.9114 & 98.3 & 98.3 & 4.32 & 22.6 & 30.5 \\
\hline B35 & 1.8519 & 1.8819 & 96.8 & 96.8 & 4.02 & 19.8 & 24.9 \\
\hline B35 & 1.8014 & 1.8306 & 94.2 & 94.2 & 3.69 & 16.9 & 19.4 \\
\hline B36@-54ㅇ $\mathrm{C}$ & 1.9122 & 1.9432 & 99.9 & 100.0 & 4.93 & 28.1 & 42.9 \\
\hline B36 & 1.8814 & 1.9119 & 98.3 & 98.3 & 4.48 & 23.9 & 33.4 \\
\hline B36 & 1.8515 & 1.8815 & 96.8 & 96.8 & 4.22 & 21.4 & 28.1 \\
\hline B36 & 1.7998 & 1.8290 & 94.1 & 94.1 & 3.68 & 16.8 & 19.3 \\
\hline B25@-54² C & 1.9119 & 1.9429 & 99.9 & 99.9 & 4.95 & 28.3 & 43.3 \\
\hline $\mathrm{B} 25$ & 1.8808 & 1.9113 & 98.3 & 98.3 & 4.45 & 23.7 & 32.8 \\
\hline B25 & 1.8526 & 1.8826 & 96.8 & 96.8 & 4.06 & 20.1 & 25.5 \\
\hline $\mathrm{B} 25$ & 1.8016 & 1.8308 & 94.2 & 94.2 & 3.66 & 16.7 & 19.1 \\
\hline
\end{tabular}

Table II. Listing of the threshold data used in Fig. 6 and Fig. 7. 